\title{
Truisms our teachers taught us
}

$\mathrm{H}$

ere are a few that have stood the test of time. Some are useful beyond plastic surgery.

\section{Do what you know first}

Meaning: When faced with a complex situation, a surgical jigsaw puzzle to piece together, find something that seems to fit and fix that. Then find the next part and so on.

This is useful in complex facial laceration repairs and whenever a task seems so big you do not know where to start.

Other applications: Do something, make a start.

2. Do not do today what you can honourably put off until tomorrow

Meaning: Do not rush at doing surgery.

- Do not get too busy.

- Save time to use for when you really need the time for urgent things. Watch and wait.

- Some things get better on their own.

- Other applications: Predict what might happen naturally.

3. When you see an abscess you are already one day late in draining it

Meaning: Take action immediately when there is no doubt.

- Other meanings: Learn when to take immediate action. Learn when to cash in your chips. Take advice, but the final decision is always yours.

\section{Do not operate on a patient who is getting better} Meaning: Remember the natural history of the disease and operate on the down slope to gain the up slope.

- Other meaning: The patient and family should be convinced surgery is necessary.

\section{No person's opinion is better than his facts} Meaning: Know the difference; most people do not.

- Other meaning: A fact requires proof. Debate the proof.

6. I would rather have a patient mad at me before surgery than after surgery

Meaning: Say no right away if you do not think you can help.

- The patient deserves the bottom line as you know it.
- Other meaning: If the patient cannot handle hearing about the risks before surgery, he or she cannot handle a real complication after surgery.

7. In general, do not do favours Meaning: It is not your fault someone wants to bump the line.

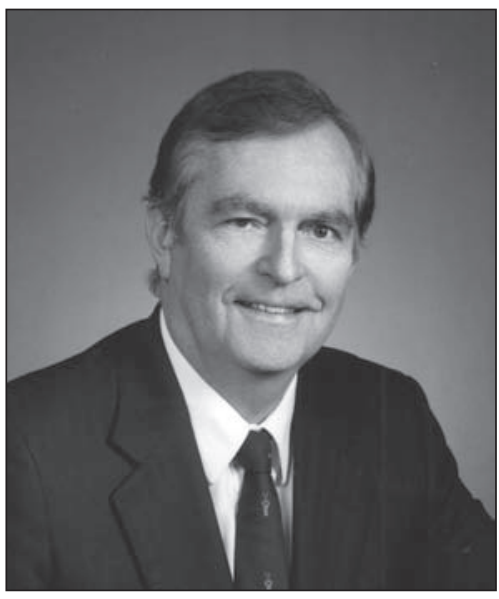

John R Taylor
- Adding an extra patient when you do not have time will seldom result in gratitude but will certainly delay everyone else that day.

8. Be kind and tolerant to older people Meaning: That's you in a few years. Do not be shocked.

- These are not necessarily the golden years!

- Repeat what you say slowly.

- Other meaning: Only if you live long enough.

9. The more obvious the problem the easier it is to improve Meaning: Do not operate when the problem is not immediately apparent.

- Other meaning: Learn how to say no.

- Saying, "I do not have the skill to achieve what you want" is a good way.

- Always say it as soon as you know.

- Your first impression is usually right.

10. Spoken like a true empirical doctor Meaning: Avoid repeated mantras.

- Keep revising. 